Research Article

\title{
Centrifuge Model Test on the Settlement of Valley-Type Loess Filled after Construction and Subjected to Rainfall Infiltration
}

\author{
Jiwen Zhang, ${ }^{1,2,3}$ Jie Cao, ${ }^{2,3} \mathrm{Bo} \mathrm{Li}^{4}{ }^{4}$ Kunye Zhou, ${ }^{5}$ and Xilin Lü ${ }^{5}{ }^{5}$ \\ ${ }^{1}$ School of Human Settlements and Civil Engineering, Xi'an Jiaotong University, Xi'an, Shanxi 710049, China \\ ${ }^{2}$ China JIKAN Research Institute of Engineering Investigations and Design, Co., Ltd., Xi'an, Shanxi 710043, China \\ ${ }^{3}$ Shaanxi Key Laboratory for the Property and Treatment of Special Soil and Rock, Xi'an, Shaanxi 710043, China \\ ${ }^{4}$ Changjiang River Scientific Research Institute, Wuhan 430010, China \\ ${ }^{5}$ Key Laboratory of Geotechnical and Underground Engineering of Ministry of Education, \\ Department of Geotechnical Engineering, Tongji University, Shanghai 200092, China
}

Correspondence should be addressed to Xilin Lü; xilinlu@tongji.edu.cn

Received 29 July 2020; Revised 7 January 2021; Accepted 18 January 2021; Published 31 January 2021

Academic Editor: Jian ZHOU; csujzhou@hotmail.com

Copyright (c) 2021 Jiwen Zhang et al. This is an open access article distributed under the Creative Commons Attribution License, which permits unrestricted use, distribution, and reproduction in any medium, provided the original work is properly cited.

With the rapid development of infrastructure construction in western China where hilly and gully areas are distributed, there are lots of large-scale filling engineering in recent years. In the area where collapsible loess is widely distributed, it is inevitable to use loess as filling material. Considering the collapsibility of loess, centrifuge model tests were conducted to study the settlement of loess fill in a valley after construction and subjected to rainfall infiltration. To provide a comparison, a centrifuge model test of loess filling body on a flat ground was conducted, and results showed that the settlement of loess fill during the construction stage is larger than the one at the postconstruction stage, and the unloading rebound deformation caused by decreasing gravity is about $15 \%$ of the deformation induced by increasing gravity. Two centrifuge model tests were conducted to study the settlement of the loess filling body in a valley; the varying characteristics of settlement and earth pressure with time at the postconstruction stage and subjected to rainfall infiltration were investigated. Differential settlement in the ground surface was observed at the postconstruction stage, and it was found to become very small under the rainfall infiltration condition. Comparison of the test results showed that insufficient compaction in the lower part of the filling body significantly increases the ground settlement at the postconstruction stage.

\section{Introduction}

To satisfy continuous increasing demand of urban space in hilly and gully areas of western China, lots of filling engineering are constructed. The ground settlement induced by self-gravity is an important issue other than the general concerned settlement which is caused by construction disturbance [1] and facility operation [2]. In those areas where loess is widely distributed, stability and settlement control are crucial to the safety and economic issues of large filling engineering. The collapsibility of loess when absorbing water may cause large ground deformation and differential settlement and then leads to severe influence and even damage to the facilities built on it. It has been found that excessive differential ground settlement shortens pavement life and even causes catastrophic failure [3]. Therefore, it is necessary to study the wetting-induced deformation of loess fill; the obtained results can provide a reference for the design and construction of loess filling engineering.

The geotechnical property of loess is sensitive to the water content, and intact loess may collapse rapidly with an increasing water content [4]. Experimental approach has been adopted to study the wetting behavior of loess $[5,6]$, and collapsing phenomenon can be clearly shown in wetting tests [7]. Consolidation and wetting test indicated that the collapse potential of remolded loess depends on the initial dry unit weight and initial water content [8]. Shao et al. [9] found that the collapsibility is mainly attributed to its interaggregate pore size. Triaxial test results showed that the 
compression behavior of intact loess is highly affected by the suction [10]. Wetting-drying characteristic has strong impact on the geotechnical properties of compacted loess [11], and the critical saturation degree necessary for wetting collapse increases with initial dry density but decreases with vertical pressure [9]. Triaxial and uniaxial compression tests conducted on undisturbed loess demonstrated that the geotechnical properties of loess are dominated by its metastable structure [12]. The shear strength of unsaturated soil was found to increase significantly with the decreasing water content [13], and the yield stress of compacted loess decreases with decreasing suction [14].

The rainfall infiltration-induced settlement of a foundation in unsaturated soil has been studied experimentally and numerically $[15,16]$. Laboratory test conducted on the mutual embedding settlement between miscellaneous fill and soft soil showed that a large particle size results in large settlement [17]. Kim et al. [18] numerically analyzed the settlement behavior of shallow foundations caused by rainfall infiltration in unsaturated soil; rainfall intensity was the major influence factor in settlement. For an embankment filled by loess, compaction degree can be useful to control the settlement when subjected to water change [19]. Loess compacted on dry side of optimum has high strength and great strength loss when soaked into water [20, 21]. Centrifuge model test provides an effective approach to explore the deforming behavior of soil subjected real stress changes [22] and water content variation, and it was shown to be able to reveal the deformation and failure of soil body made of loess [23]. Centrifuge model test was also used to study the settlement of strip footing on loess, and the results showed that the footing settlement significantly increases with increasing rising water table [24]. Although centrifuge model test provides an effective way to study the settlement of loess filling, there is still a lack of research on the deformation of filled loess in valleys which is induced by gravity and rainfall infiltration.

Existing research provided useful information for the settlement estimation of loess ground induced by force and water infiltration. However, those studies mainly concentrated on soil behavior testing and foundation settlement analysis, and the deforming mechanism of newly filled loess induced by wetting still needs further study. The objective of this paper is to investigate the deformation characteristics of large loess filling engineering by centrifuge model tests. The gravity-induced settlement of newly filled loess and the deformation caused by rainfall infiltration were explored. The paper is organized as follows. After the introduction of the paper in the first part, the second part is the description of materials and methods, the third part is the test results and discussions, and the fourth part is conclusion.

\section{Methods and Instrumentation}

2.1. Testing Materials. The remolded $Q_{2}$ loess was used in the centrifuge model tests. Specimens were obtained from a large filling engineering at Yan'an city, Shanxi province in
China. The loess material was mainly constituted of detrital minerals and clay minerals; the detrital minerals are mainly quartz, feldspar, etc., and clay minerals mainly include hydromica, kaolinite, and montmorillonite. The tested loess specimen was composed of high content of silt components, and it had typical characteristics of loose structure, uniform texture, large pores, no bedding, and containing a large amount of white mica pieces and a small number of snail fossils. The specific gravity of soil particle was 2.73 , and the liquid limit and plasticity limit were 29.89 and 16.77 . The compaction characteristics of the loess were studied by both light compaction test and heavy compaction test. As shown in Figure 1, the compaction curve obtained from light compaction test gives out the maximum dry density $1.773 \mathrm{~g} / \mathrm{cm}^{3}$, and the corresponding optimum water content is $16.0 \%$. The compaction curve obtained from heavy compaction test gives out the maximum dry density $1.944 \mathrm{~g} / \mathrm{cm}^{3}$, and the corresponding optimum water content is $12.1 \%$. The permeability coefficient of loess used in the centrifuge test was $3.17 \times 10^{-5} \mathrm{~cm} / \mathrm{s}$ when its saturation ratio was $16 \%$ and dry density was $1.65 \mathrm{~g} / \mathrm{cm}^{3}$.

\subsection{Test Setup of Loess Filling Body on Flat Ground.} Centrifuge model tests were conducted on the CKY-200 geotechnical centrifuge facility at Changjiang river scientific research institute. As shown in Figure 2, the CKY-200 has a maximum centrifuge acceleration of $200 \mathrm{~g}$ and effective radius of $3.7 \mathrm{~m}$. In a centrifuge model test, the prototype behavior is approximated by scaling laws [25]. Scaling factors can be introduced by choosing a set of basic physical properties to be independent and deriving the scaling factors for other properties [26]. On the basis of similarity between the model and prototype, a $1 / n$ scale centrifuge model behaves like its prototype when the acceleration rate is $n g$. The scaling law adopted in the centrifuge model test is shown in Table 1. According to the scaling law, the settlement obtained from model test should be amplified 100 times to get the settlement in prototype, while the stress and strain in prototype and in the model test were the same. A model box with a size of $1000 \mathrm{~mm}$ (length) by $400 \mathrm{~mm}$ (width) by $800 \mathrm{~mm}$ (depth) was used. The front side of the box is made of transparent perspex through which the deforming process can be clearly viewed during testing process. The test program is shown in Table 2 . T1 test was carried on a filled valley which is uniformly compacted; it provides a comparison for the settlement analysis of filled body in a valley. After drying in the sun, the loess specimen was mixed with a certain content of water to make the water content of the specimen $12 \%$. The specimen was kept 24 hours to make water distribution homogenous. The soil was filled into the model container layer by layer, and then each layer was compacted. The model box was put into the centrifuge apparatus, three displacement transducers were placed at the ground surface, and a HD camera was equipped facing the transparent wall. The acceleration rate was raised from $0 \mathrm{~g}$ to $100 \mathrm{~g}$. For each $20 \mathrm{~g}$ increase, pause for enough time to make sure the gravity-induced deformation was reached. The acceleration 


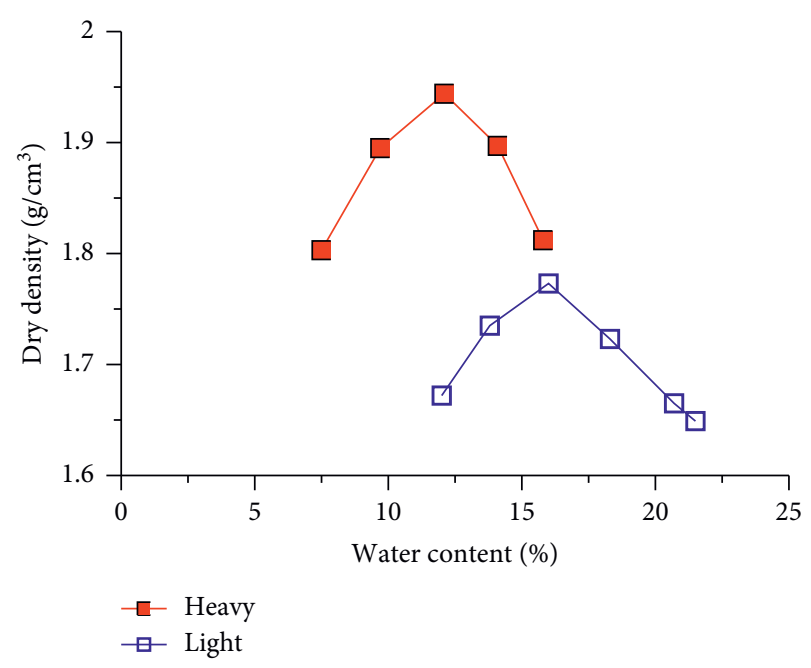

FIgure 1: Compaction curves.

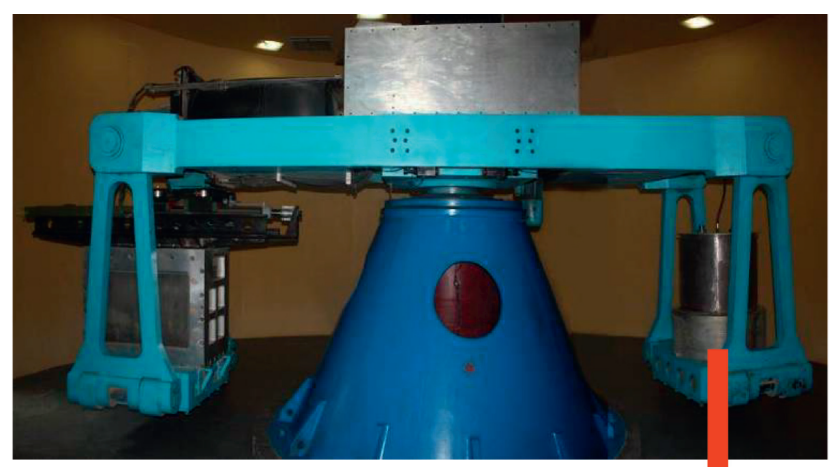

(a)

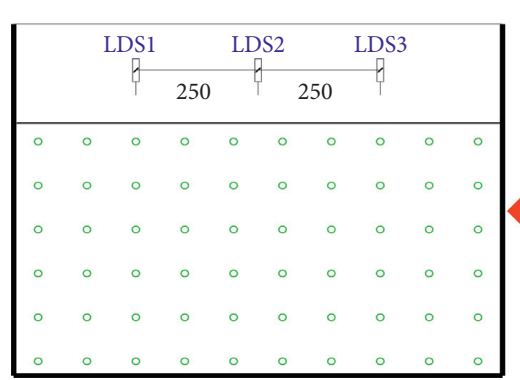

(c)

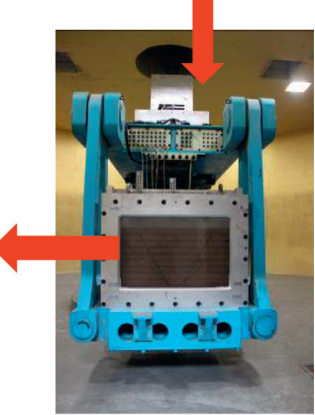

(b)
Figure 2: Model test conducted at CKY-200 geotechnical centrifuge facility. (a) Centrifuge facility. (b) Model box. (c) Sketch map of model test.

rate was hold at $100 \mathrm{~g}$ for $45 \mathrm{~min}$ and then was decreased. During the centrifuge model test, the settlement of ground surface was measured, and pictures were automatically taken at a fixed time interval.

2.3. Test Setup of Loess Filling Body in a Valley. The setup of centrifuge model test on the loess filling body in a valley is shown in Figure 3. The height of the filling body is $60 \mathrm{~cm}$. The slope angle of the model slope is $30^{\circ}$. Displacement transducers were distributed on the ground surface, and pressure sensors were placed at different depths to record the variation of earth pressure during testing. Pressure sensors were installed during the preparation of model layer by layer, and displacement transducers were installed after the model was completed. The locations of the surface settlement measuring points and earth pressure measuring points are shown in Figure 3. The test program for loess filling body in a valley is shown in Table 2 . In test T2, filled loess was uniformly compacted; the water content is $12.0 \%$ and dry density is $1.65 \mathrm{~g} / \mathrm{cm}^{3}$, which corresponds to compactness of 0.85 . In test $\mathrm{T} 3$, the filled loess is nonuniformly compacted; the dry density of the upper half was 1.65 , and the dry density of the lower half was 1.56 , which corresponds to compactness of 0.80 . The reason that the filled loess was not compressed enough was to study the gravity-induced settlement. The model tests were carried out under $100 \mathrm{~g}$, and the total height of the filling engineering in prototype was $60 \mathrm{~m}$. The slope was modeled by concrete; it was rigid and has very low permeability so as to be in accordance with the bedrock in real engineering. The model slope was preinstalled into the model box.

Unsaturated remodeled loess was used to fill the valley. To guarantee the quality of filling body, the model was composed of 6 layers with $10 \mathrm{~cm}$ thickness of each layer. By controlling the dry density and homogeneity, the model was compacted based on the testing scheme. As shown in Figure 4 , the surface of each soil layer was scratched before the next layer was filled. When the filling height reached the designed height, the surface was evented.

In order to monitor the surface settlement, laser displacement transducers were installed at the ground surface. The layout of displacement transducers is shown in Figure 3. The transducer has maximum measuring range of $0-160 \mathrm{~mm}$ and the measurement accuracy is $0.01 \mathrm{~mm}$. Marking points were attached onto the slope side to track deformation pattern. A high resolution digital camera was equipped in front of the box to take pictures during the test. Those obtained pictures were processed by particle image velocimetry (PIV) to trace the evolution of deformation pattern. To monitor the variation of earth pressure, pressure transducers were located at the depth of $20 \mathrm{~cm}, 40 \mathrm{~cm}$, and $60 \mathrm{~cm}$. The measuring range of the pressure transducer is $0-2 \mathrm{MPa}$ and the error is $\pm 1 \%$.

2.4. Equipment of the Rain System. In order to realize rainfall infiltration during the test, an atomizing nozzle structure suitable for centrifugal field was adopted. As shown in Figure 5, the rain system consisted of 6 atomizers and is connected to a water supply system through water supply tubes. Using jet air with certain pressure to atomize water, raindrops in centrifugal field can be very small, so it can effectively simulate the prototype of rainfall. The rainfall intensity can be conveniently controlled by adjusting the air pressure from the gas supply, and the rainfall time can also be easily controlled by the external water supply. The rainfall sprinklers were evenly arranged in the middle section of the model box, with a horizontal spacing of $15 \mathrm{~cm}$, which can cover most areas of the ground surface. 
TABLE 1: Scaling law in the centrifuge model test.

\begin{tabular}{lcc}
\hline Parameter & Scaling law & Centrifuge model dimension at $n$ times $g$ \\
\hline Length, $l$ & $S_{l}=1 / n$ & 0.01 \\
Displacement, $S$ & $S_{s}=1 / n$ & 0.01 \\
Angular displacement, $\theta$ & $S_{\theta}=1$ & 1 \\
Strain, $\varepsilon$ & $S_{\varepsilon}=1$ & 1 \\
Stress, $\sigma$ & $S_{\sigma}=1$ & 1 \\
Elasticity modulus, $E$ & $S_{E}=1$ & 1 \\
Time, $t$ & $S_{t}=1 / n^{2}$ & 0.0001 \\
Gravity, $G$ & $S_{G}=n$ & 100 \\
\hline
\end{tabular}

TABle 2: Test program.

\begin{tabular}{|c|c|c|c|c|c|}
\hline Test no. & Type & Acceleration (g) & Prototype size $(\mathrm{m})$ & Slope angle $\left({ }^{\circ}\right)$ & Filling loess (water content $(\%)$ and dry density $\left.\left(\mathrm{g} / \mathrm{cm}^{3}\right)\right)$ \\
\hline $\mathrm{T} 1$ & Foundation & & 55 & - & $16.0 \%, 1.65$ \\
\hline $\mathrm{T} 2$ & Valley & 100 & & & $12.0 \%, 1.65$ \\
\hline T3 & Valley & 100 & 60 & 30 & $\begin{array}{l}\text { Upper half: } 12.0 \%, 1.65 \\
\text { Lower half: } 12.0 \%, 1.56\end{array}$ \\
\hline
\end{tabular}

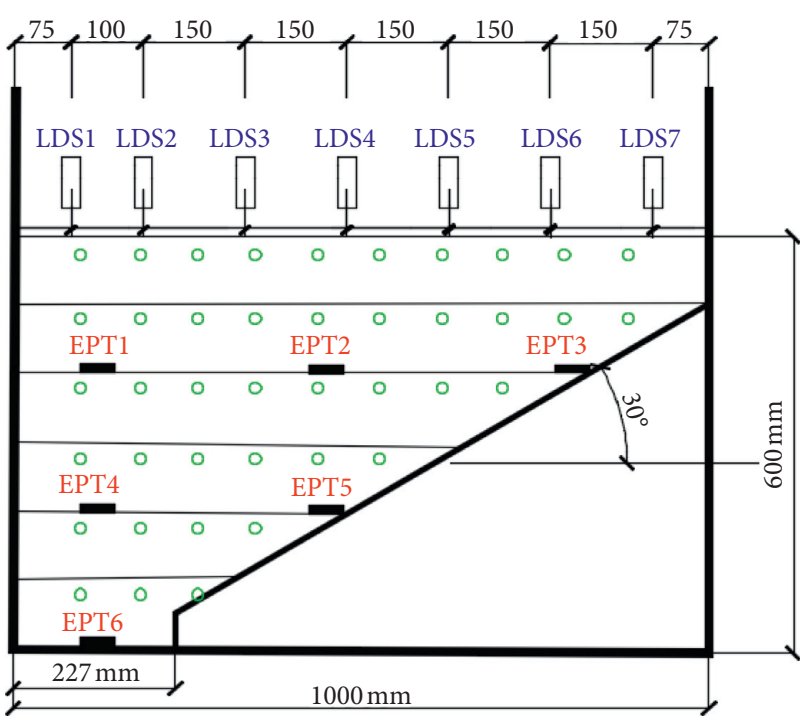

Figure 3: Setup of model test (T2 and T3) (EPT means earth pressure transducer and LDS means laser displacement sensor; units are $\mathrm{kPa}$ and $\mathrm{mm}$ ).

\subsection{Testing Procedures of Loess Filling Body in a Valley.}

Tests were carried out to investigate the ground settlement caused by the consolidation of loess fill and rainfallinduced wetting deformation separately. The first stage is to determine the settlement of filled body after construction, and the second stage is to study the settlement induced by rainfall infiltration. After the setup of model and instrumentation, the model container was arranged into the centrifuge facility. The centrifuge was started, and then the acceleration gradually reached $100 \mathrm{~g}$ and was kept constant until the stable settlement was reached. After the testing of this first stage, the centrifuge machine was stopped to install the artificial rain system, and the deformation sensors were adjusted and zeroed out. The model container was transferred into the centrifuge machine again, and the acceleration was gradually increased to $100 \mathrm{~g}$. When the settlement reached the stable state, the artificial rain system was turned on. The rain flowed into the ground surface with a speed of $200 \mathrm{~mm} / \mathrm{h}$ and lasted for $420 \mathrm{~s}$, which corresponds to a long period of moderate rain with intensity of $2 \mathrm{~mm} / \mathrm{h}$ for 48.7 days. During the testing process, images were taken by a HD camera through the transparent wall to track the deformation process of filled loess.

\section{Test Results and Discussion}

3.1. Settlement of Loess Fill on Flat Ground. By reading the data obtained from laser displacement transducers installed at the ground surface, the ground settlement of loess fill at whole testing process can be obtained. The varying characteristics of settlement and gravitational acceleration with time are shown in Figure 6. The settlement at ground surface increases as the acceleration increases from $0 \mathrm{~g}$ to $100 \mathrm{~g}$, and then it decreases as the acceleration is decreased. When the $100 \mathrm{~g}$ was kept, the settlement converged, indicating that the consolidation of ground induced by soil gravity was completed. The obtained curve of settlement and acceleration rate can be divided into three stages. The first stage corresponds to the increase of acceleration rate from 0 to $100 \mathrm{~g}$ step by step with each step $20 \mathrm{~g}$. In this stage, the increase of acceleration results in the increase of the gravity, so the settlement at construction period can be reflected. The second stage is the settlement when the acceleration is kept at $100 \mathrm{~g}$. As shown in Figure 6, the continuously increase of settlement is caused by the incomplete consolidation in the first stage and secondary consolidation of filled loess under the condition that the effective stress is basically unchanged (i.e., induced by creep). The settlement converged as the acceleration holds for enough time, indicating that the consolidation of ground was completed. The third stage corresponds to the decrease of acceleration rate from $100 \mathrm{~g}$ to $0 \mathrm{~g}$; the decreasing settlement denotes the unloading rebound deformation caused by a reduced gravity stress. The obtained maximum settlement was $14.5 \mathrm{~mm}$, which corresponds to $1.45 \mathrm{~m}$ in the prototype. The rebound deformation was about $15 \%$ of the deformation induced by increasing gravity. 


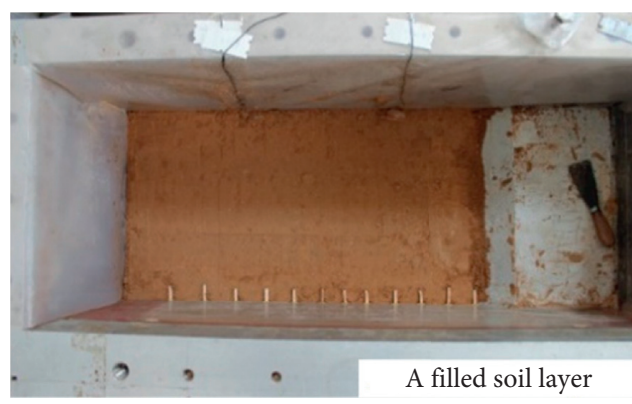

(a)

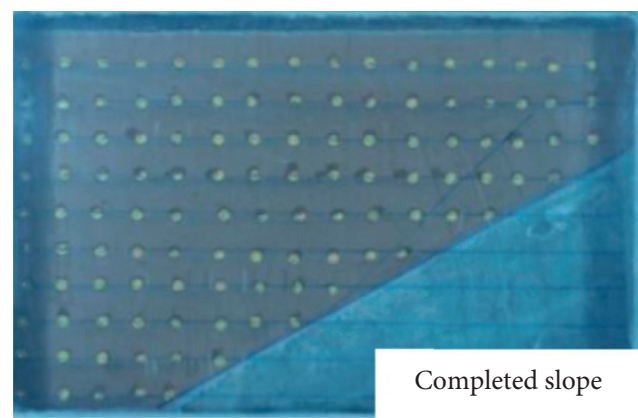

(c)

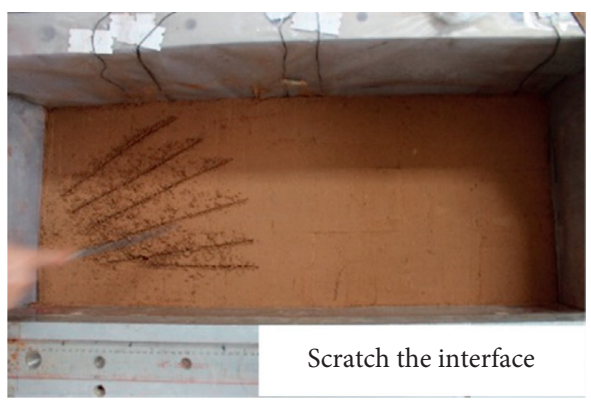

(b)

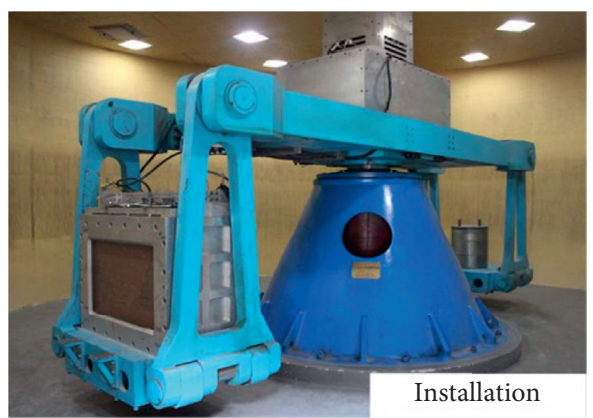

(d)

FIGURE 4: The preparation of the loess filling model in a valley: (a) filling process; (b) scratching process; (c) completed model; (d) model installation.

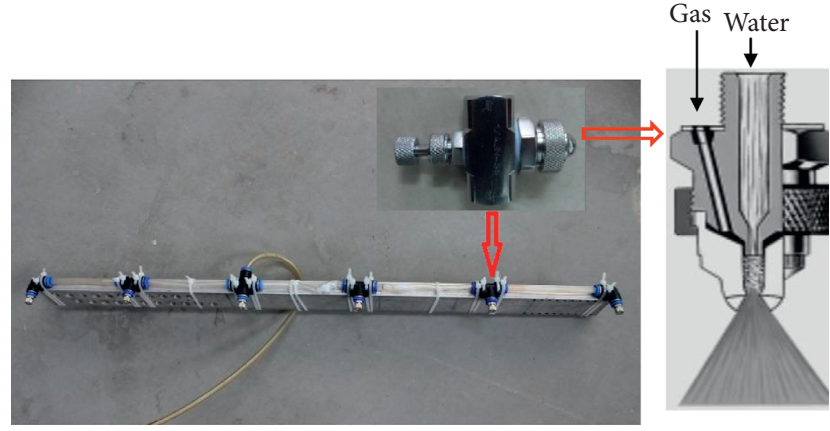

FIGURE 5: Artificial rain system.

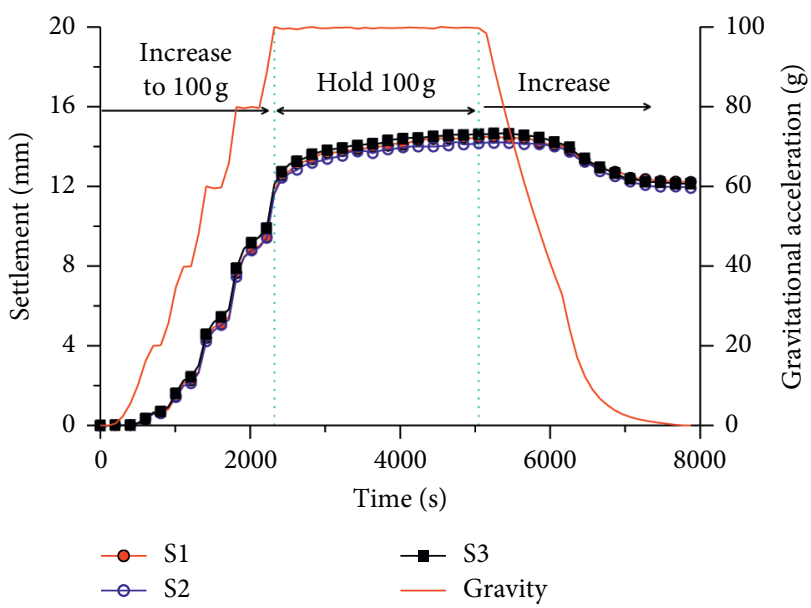

FIGURE 6: Settlement of the ground surface (T1).
Pictures taken before and after test were analyzed by PIV analysis, and a vector map of particle displacements was produced. The magnitude and direction of the relative movement between two images are shown in Figure 7. In general, the deformation demonstrates a homogenous pattern in a certain altitude as long as it is far away from the model box boundary. The deformation of soil close to the boundary is smaller than that one far away from it, indicating a boundary effect. However, the boundary effect weakens rapidly as the soil is away from the side wall and even disappears if the soil is about $20 \mathrm{~cm}$ away from the wall.

After the test was finished, samples were collected from the depth of 20,40 , and $55 \mathrm{~cm}$. The dry density of the specimen was tested, and the obtained compaction degree of the sample was $0.85,0.85$, and 0.86 . One-dimensional consolidation compression tests were conducted, and the obtained curves of void ratio of soil and pressure (e-p curve) are shown in Figure 8. It clearly shows that the deeper the soil in the tested model, the less compressibility it has. The calculated compression coefficient $\mathrm{a}_{1-2}$ was $0.19,0.22$, and $0.16 \mathrm{MPa}^{-1}$, so the tested soil can be classified as medium compressibility soil.

3.2. Settlement of Loess Fill in a Valley at Construction and Postconstruction Stages. As the acceleration rate increased with time which is shown in Figure 9, the variation of earth pressure at different depths was monitored by the distributed earth pressure transducer. Since EP1 (EP means earth pressure) transducer did not work, EP2, EP4, and EP6 at the depth of 20,40, and 60 were obtained, and the results are shown in Figure 10. Pressures increase rapidly from the 


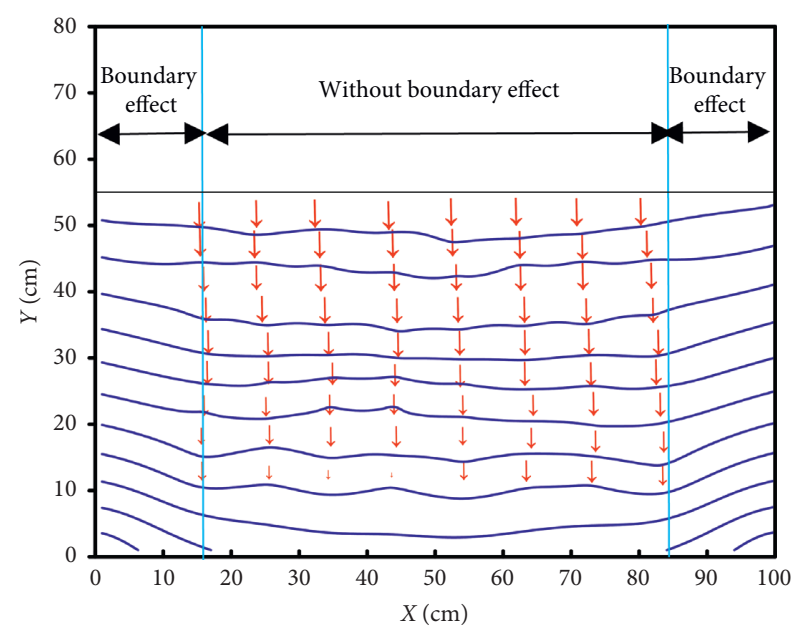

Figure 7: Spatial distribution of the ground settlement (T1).

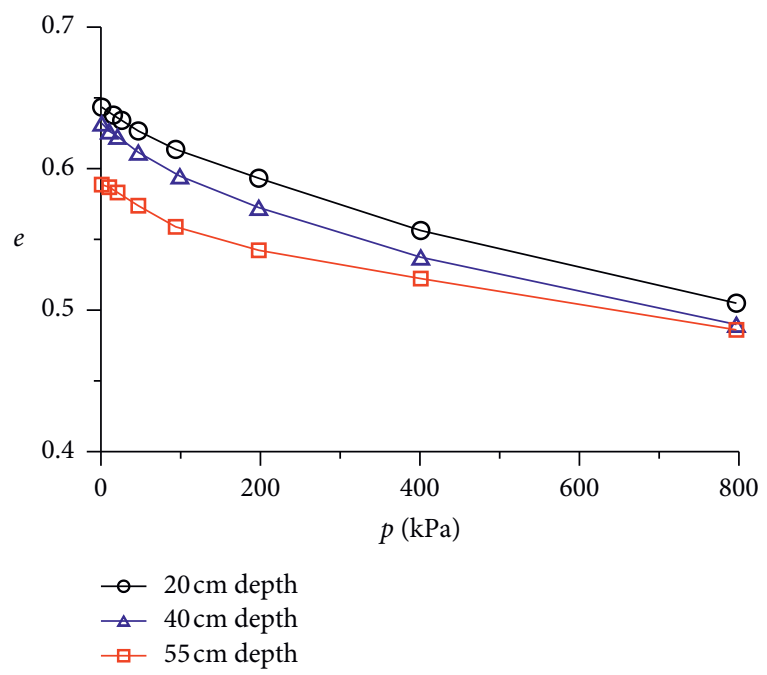

Figure 8: $e-p$ curve obtained from tests.

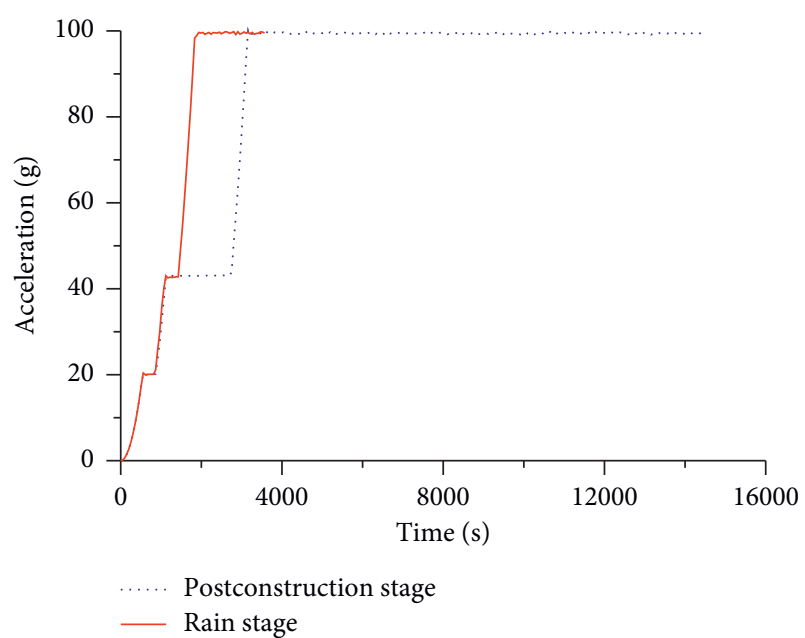

FIgURE 9: The increase of acceleration rate with time. values at initial state and reach stable values at the time of $3160 \mathrm{~s}$. The stable values at these depths are $368 \mathrm{kPa}, 753 \mathrm{kPa}$, and $1155 \mathrm{kPa}$. The pore-water pressure and water content were not monitored during the testing process, so the suction stress and effective stress cannot be obtained, and this is the weaknesses of the test. However, since the total stress in the soil body was obtained, the ultimate settlement can be analyzed by assuming the total stress turns to be effective stress by assuming that pore pressure totally dissipates. Avoiding the monitoring of the effective stress and suction, the testing procedure can be largely simplified, and the deformation mode and ultimate value can be obtained without loss of accuracy.

By reading data from the displacement sensors S1 to S7 distributed among the valley centerline in the ground surface, the settlement variation is shown in Figure 11. As the acceleration rate increases, the ground surface settlement accumulates and shows a hyperbolic curve. The ground deformation is composed of soil compression induced by the increased gravity force and consolidation of the soil layer. As the acceleration rate gradually increases to $100 \mathrm{~g}$, the settlement increases rapidly, implying that gravity-induced compression dominates the deformation of filling body. As the acceleration rate reaches $100 \mathrm{~g}$ after $3160 \mathrm{~s}$ and holds at $12000 \mathrm{~s}$, the increasing rate of deformation becomes small. The reason is that the loess is in unsaturated state; the deformation induced by consolidation is mostly completed in the process of increasing gravity. Figure 11(a) gives the ground settlement of homogenous filling body, in which the water content of filling material is $12.0 \%$, and the dry density is 1.65 . Figure $11(\mathrm{~b})$ gives the ground settlement of inhomogeneous loess fill; the water content of filling material is $12.0 \%$, but the dry densities in lower and upper half are different, which are 1.56 in lower half and 1.65 in upper half. Since transducer was broken during the test, S5 did not give out data. Comparison of the test results shows that the insufficient compaction in the lower half part of the filled body significantly increases the ground settlement at postconstruction stage. In order to reduce the settlement of filling body, the filling material in lower part should be checked during construction process to make sure it was densified enough. To further show the evolution of ground settlement, the distribution of ground surface settlement is shown in Figure 12. The settlement attains the largest value at the valley center, and it shows a decreasing trend as the monitoring point is away from the centerline.

By processing the high solution pictures using PIV image analysis, the settlement of whole cross section of loess-filled valley is shown in Figure 13. It clearly shows that the deformation concentrates on the left side, implying that large settlement occurs at the valley center. As the distance of the monitoring points from the center increases, the settlement decreases, and the horizontal component of deformation becomes obvious. Due to the existence of differential settlement, fissures occurred at the ground surface. As shown in Figure 14, the fissure width obtained from test T3 was larger than the one in test T2, and this is caused by a larger differential settlement in the test T3. 


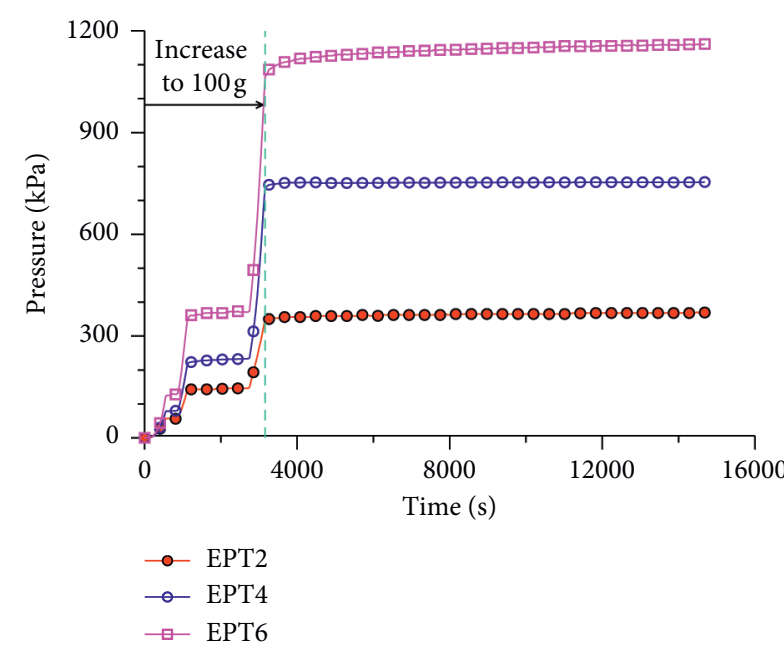

(a)

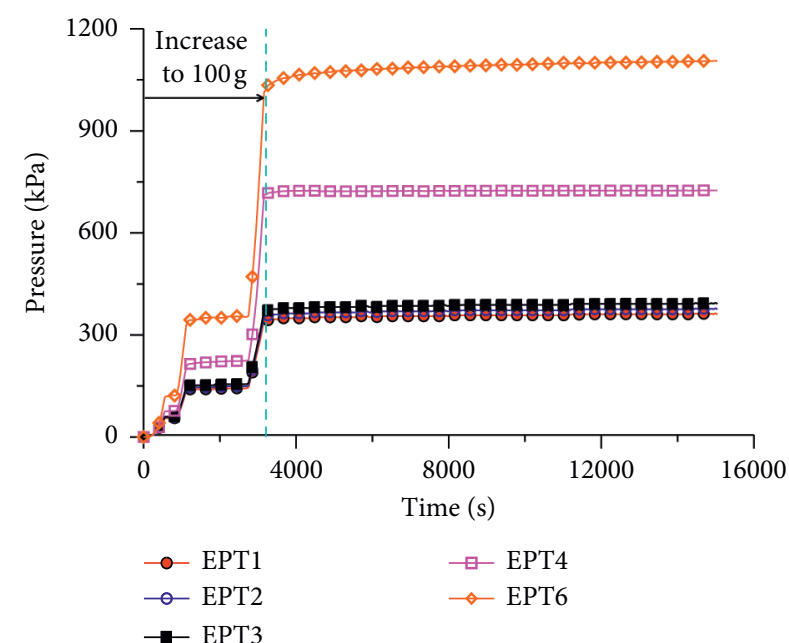

(b)

FIgURE 10: The variation of earth pressure with time: (a) T2; (b) T3.

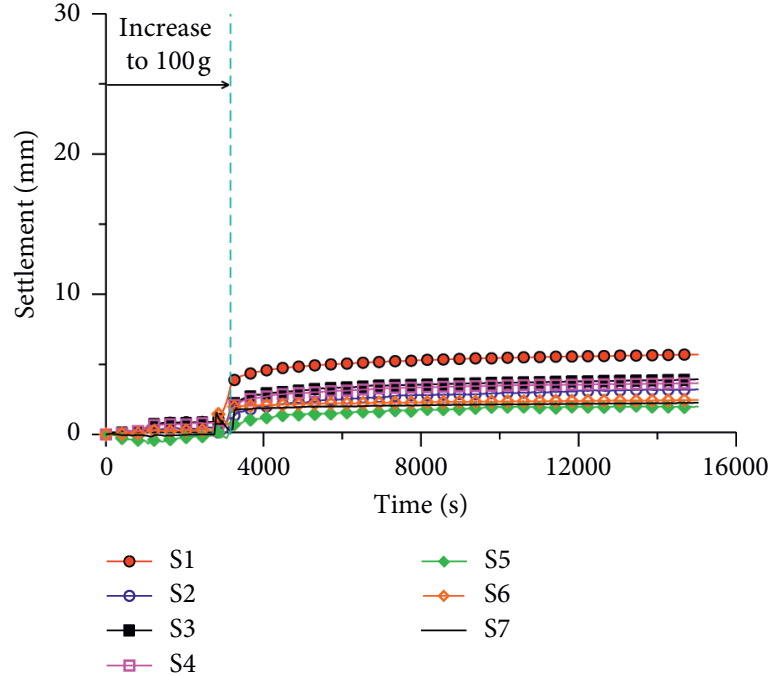

(a)
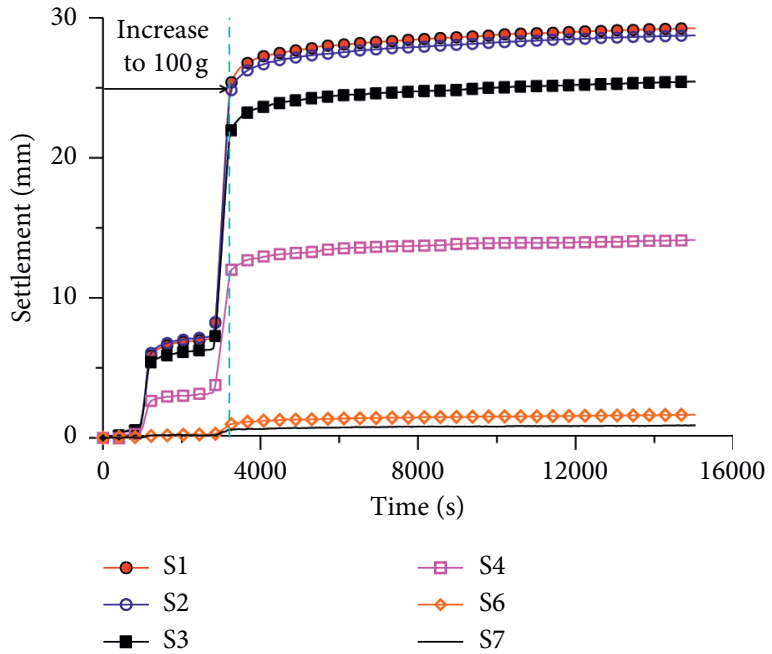

(b)

FIGURE 11: The increasing trend of the ground surface settlement at the postconstruction stage: (a) T2; (b) T3.

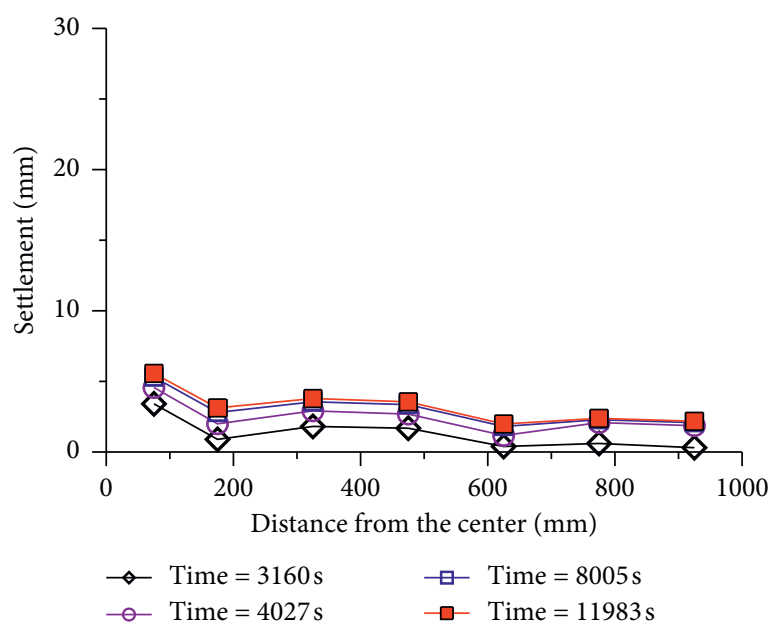

(a)

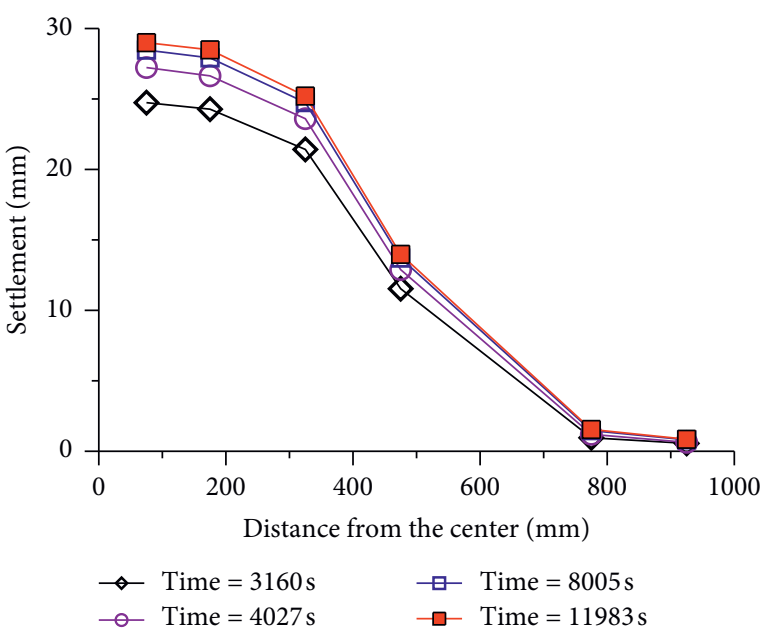

(b)

FIGURE 12: The distribution of the ground surface settlement: (a) T2; (b) T3. 


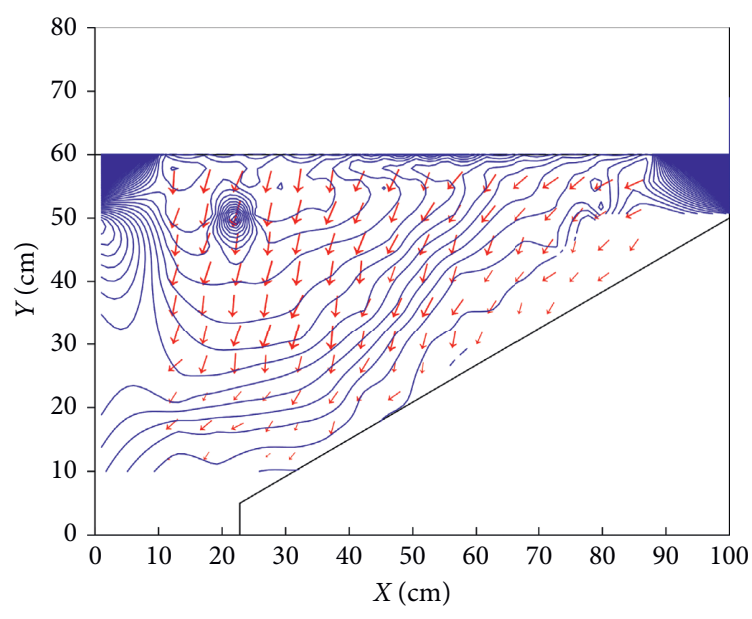

(a)

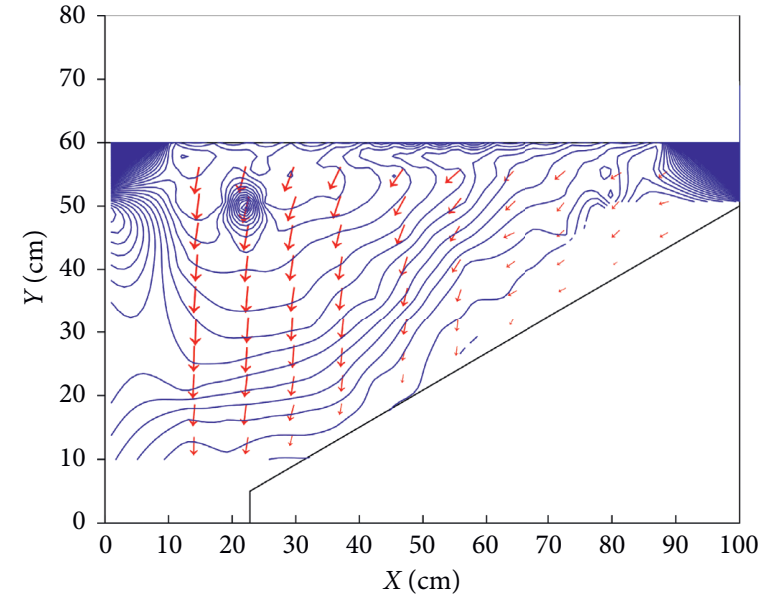

(b)

FIGURE 13: The deformation pattern at the postconstruction stage: (a) T2; (b) T3.

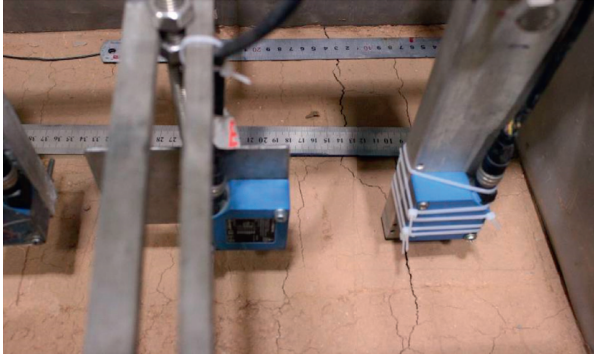

(a)

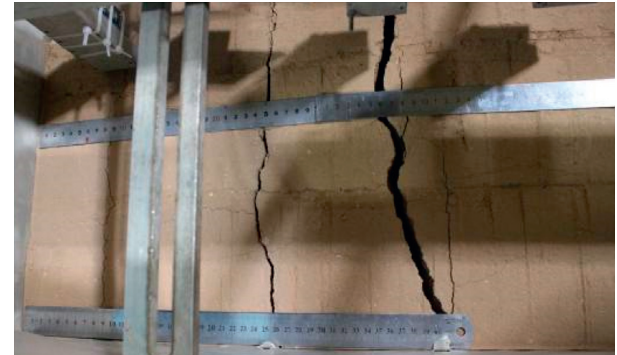

(b)

Figure 14: Fissures at the ground surface: (a) T2; (b) T3.

3.3. Settlement of Loess Fill in a Valley Induced by Rainfall Infiltration. In order to investigate the settlement induced by rainfall infiltration, rainfall system was equipped after the centrifuge model testing was stopped for a short while. After the acceleration rate reached the stable state again, the gravityinduced settlement was recovered. The rain system was then turned on and lasted for $420 \mathrm{~s}$. As rainfall infiltrating, earth pressure in the ground increases and an obvious settlement can be observed. As shown in Figure 15(a), the earth pressure at depth of $20 \mathrm{~cm}$ shows a very slight change, and the earth pressure at the depth of $60 \mathrm{~cm}$ shows a large increase. The changing characteristic of pressure indicates an increase of soil weight induced by rainfall infiltration. In test T3, the earth pressure at depth of $20 \mathrm{~cm}$ shows a slight increase as similar to test T2, but the earth pressures at the depth of $40 \mathrm{~cm}$ and $60 \mathrm{~cm}$ do not show an obvious increase. The ground settlements induced by gravity recovery and rainfall infiltration are shown in Figure 16, and the settlement solely induced by rainfall infiltration is shown in Figure 17. The water infiltration at the beginning causes a rapid increase in the ground settlement, and then the settlement approaches to a constant value. The ground surface settlement induced by gravity recovery becomes large as the monitoring point is close to the valley center; sensor S1 gives the largest and S7 gives the smallest settlement. The thicker the filled soil, the larger the ground settlement. The ground surface settlement induced by rainfall infiltration shows a different pattern, S6 gives out the largest settlement, and smaller settlements are given by S4, S5, S1, S2, and S7. In test T2, S7 gives out a larger settlement than S1, S2, and the early stage of S5 and S6; this may be caused by a heavier rainfall in this sensor location S7. Generally, rainfall infiltration-induced ground settlement is large in the middle valley, but it becomes small at the model edge due to the confinement of valley geometry. The settlement of the whole cross section was also obtained by analyzing the images taken during the test, and the results are shown in Figure 18. The deformation patterns in both tests are similar. As the distance of the monitoring points from the center increases, the horizontal component of deformation becomes obvious.

\section{Discussion}

A centrifuge test was conducted on the settlement of a newly filled ground by unsaturated loess, and the obtained settlement can be categorized into three stages that are induced by increasing gravity, consolidation, and decreasing gravity. As the acceleration rate increases, the settlement of the ground surface accumulates and shows a hyperbolic curve. The ground settlement is composed of the compression and consolidation of soil induced by the increased gravity force. As the acceleration 


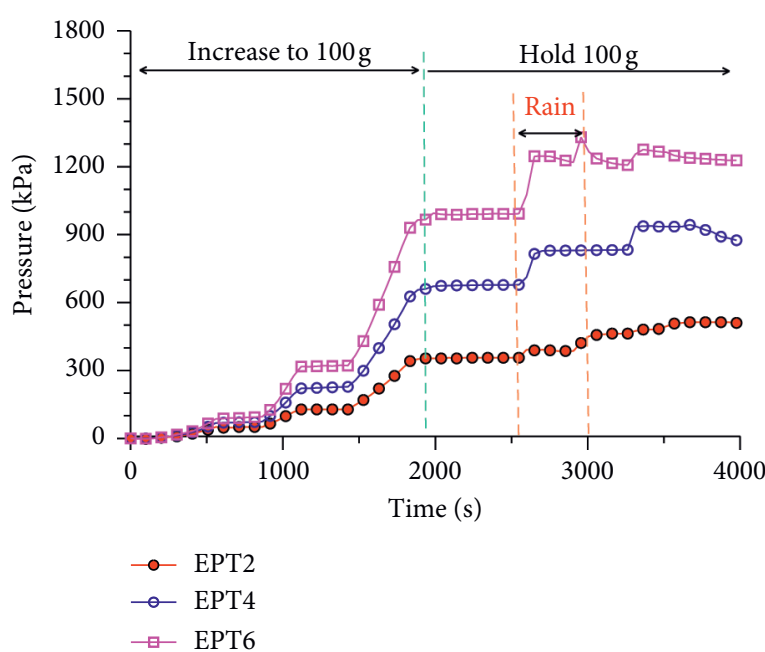

(a)

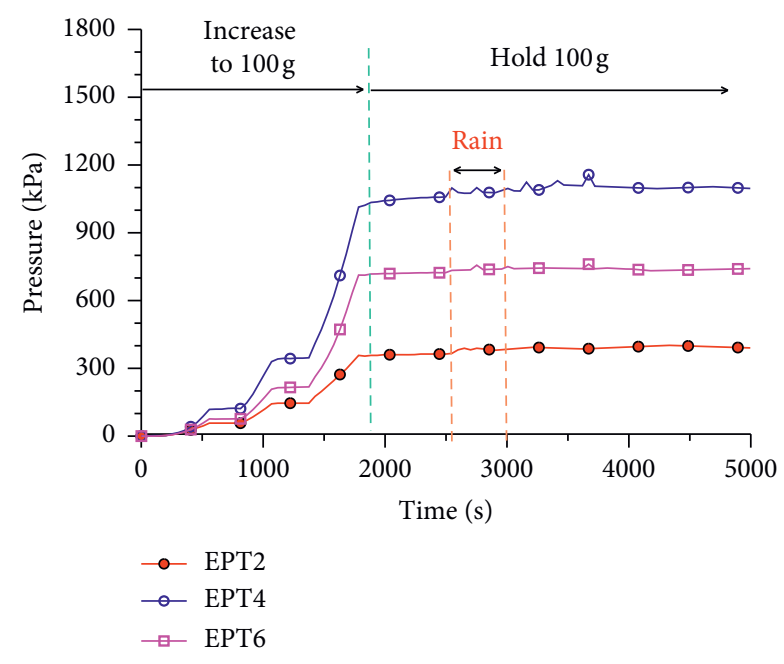

(b)

Figure 15: The earth pressure under the rain condition: (a) T2; (b) T3.

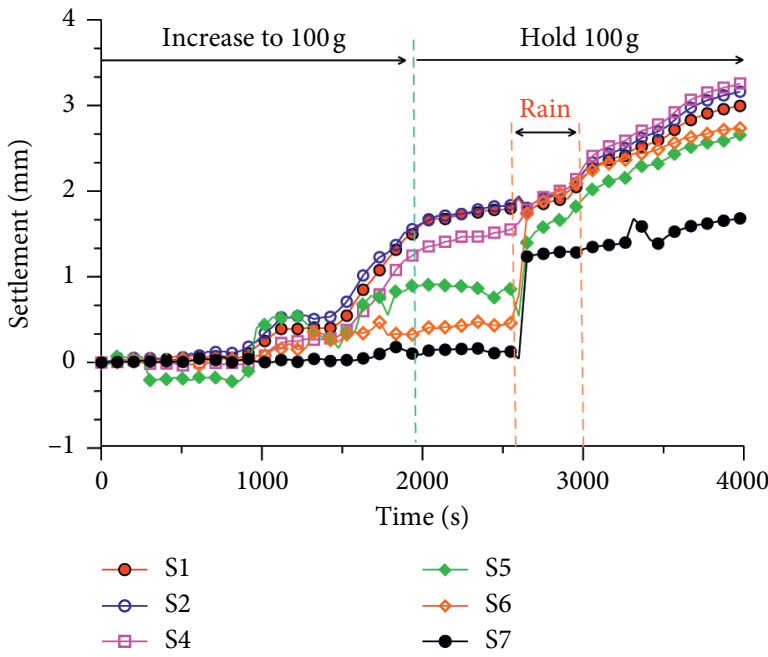

(a)

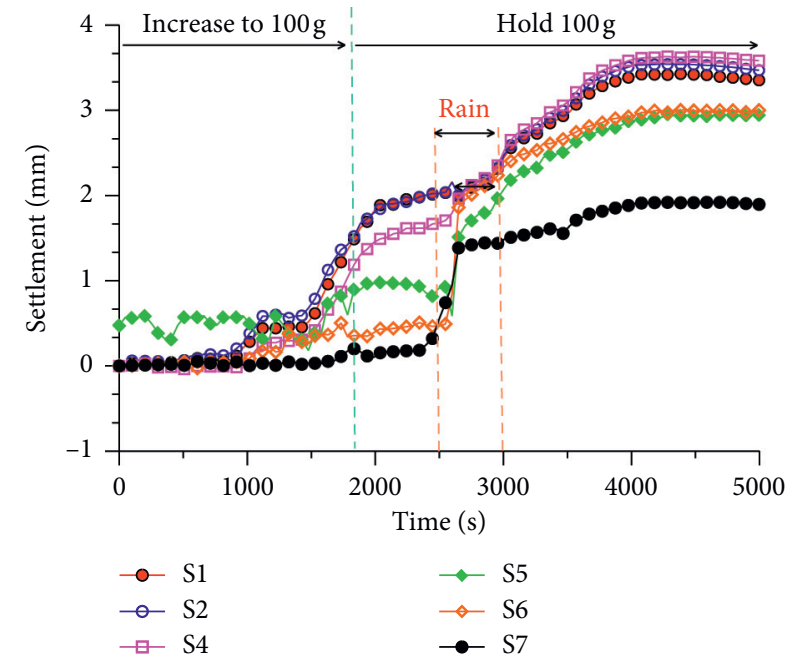

(b)

FIgURE 16: The ground surface settlement under gravity recovery and rain infiltration conditions: (a) T2; (b) T3.

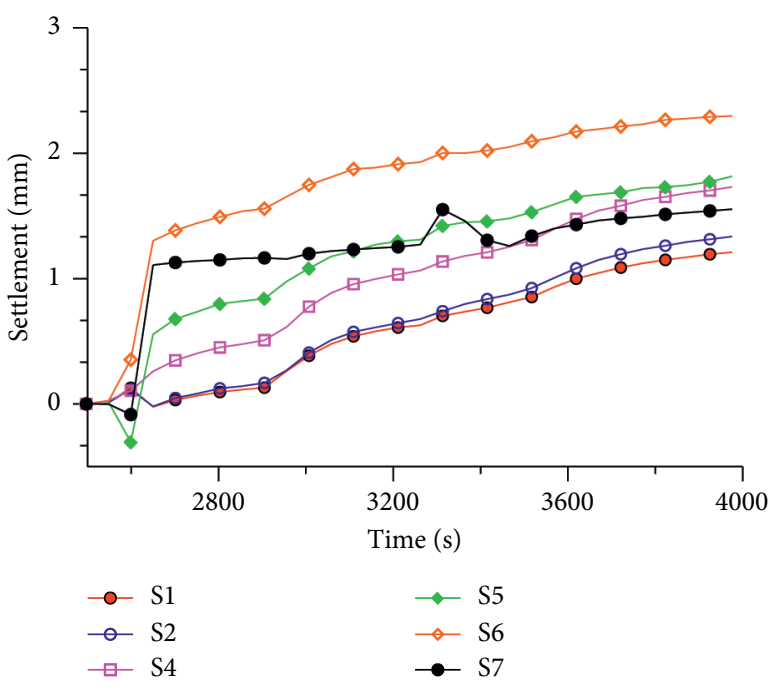

(a)

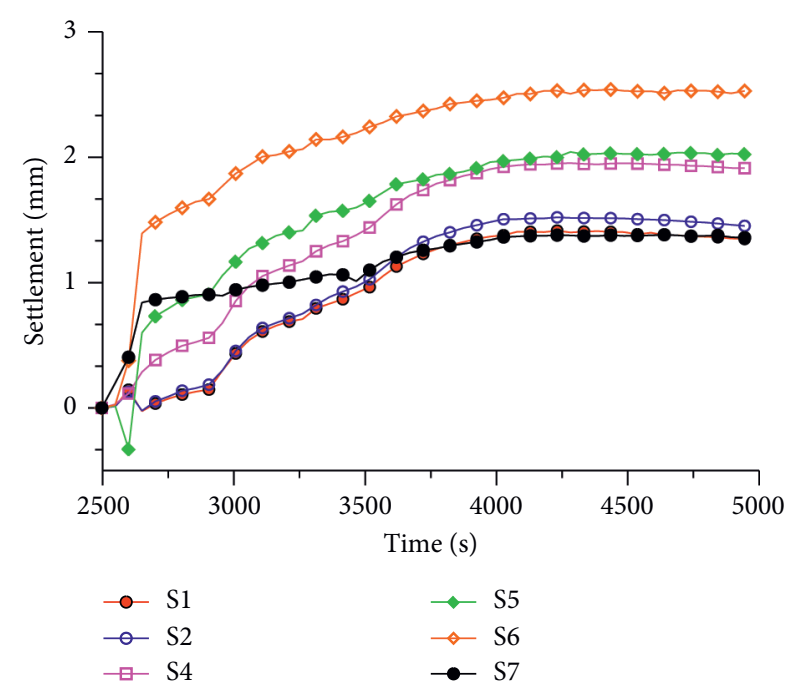

(b)

FIGURE 17: The ground surface settlement solely caused by rain infiltration: (a) T2; (b) T3. 


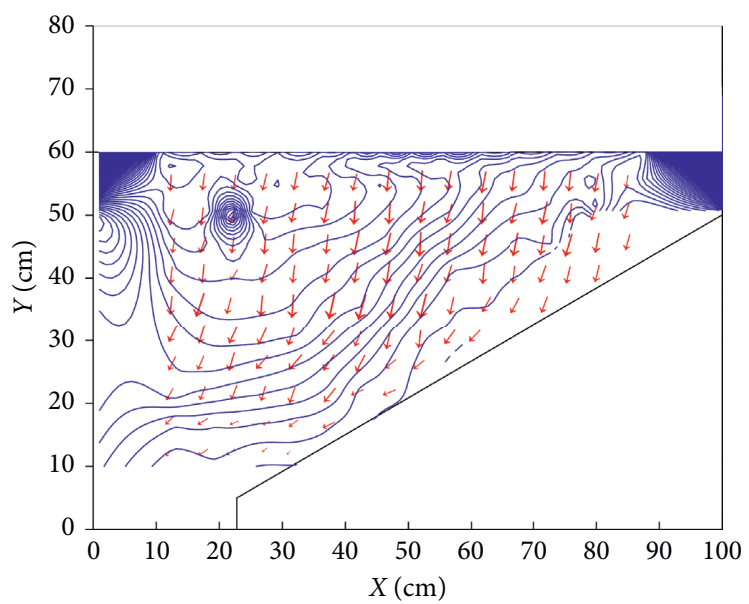

(a)

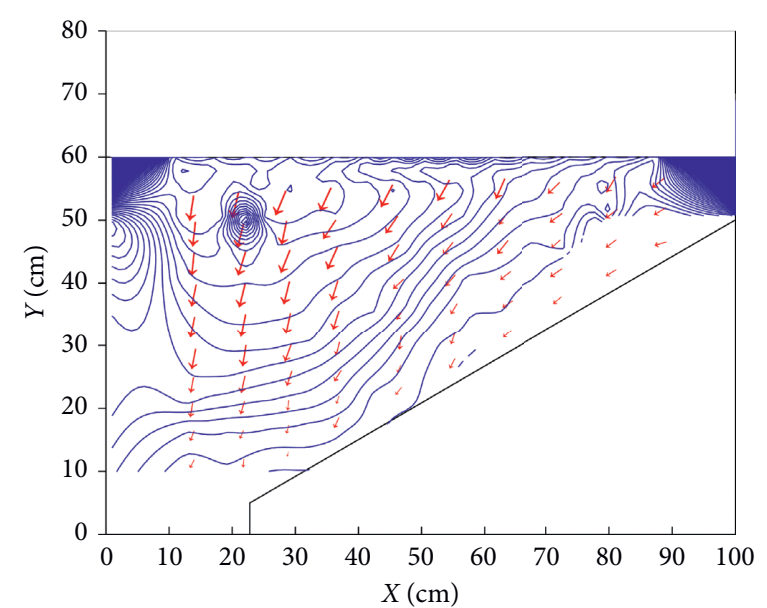

(b)

FIGURE 18: The deformation pattern caused by rain infiltration: (a) T2; (b) T3.

rate gradually increases to $100 \mathrm{~g}$, the settlement increases rapidly. Settlement continuously increases when the acceleration holds at $100 \mathrm{~g}$, and it is caused by two factors. One factor is the incomplete consolidation during the increasing stage of gravity, and the other factor is the secondary consolidation of filled loess under the condition that the effective stress is basically unchanged (i.e., induced by the creep of loess). The unloading rebound deformation induced by a decreasing gravity is about $15 \%$ of the deformation induced by increasing gravity, implying that the consolidation of loess in increasing gravity process dominates the settlement of the filling body.

Two centrifuge model tests were conducted to study the settlement of loess fill in a valley, and the ground settlement, deformation pattern of the filling body, and the earth pressure at construction, postconstruction, and rainfall infiltration stages were monitored and analyzed. Settlement profile indicates that the largest value occurs at the centerline location of valley, and as the distance of monitoring points from the valley center increases, the settlement generally shows a decreasing trend. Rainfall infiltration causes an increase in the ground settlement and quickly approaches to a stable value, and the settlement induced by rain infiltration is much smaller than the settlement induced by soil gravity. Rainfall infiltration-induced ground settlement is large in the middle filling body, and it becomes small at the model edge due to the confinement of valley geometry. Comparison of the test results shows that the insufficient compaction in the lower half part of the filling body significantly increases the ground settlement at postconstruction stage. In order to reduce the settlement of loess fill, the filling in the lower part should be densified enough. Since the rainfall infiltration-induced settlement mainly concentrates on the shallow layer of loess fill, it is slightly affected by the insufficient compaction in the lower half part.

\section{Conclusions}

Centrifuge model tests were conducted to investigate the deformation characteristics of filled loess in a valley. According to the monitored displacement at the ground surface and image analysis on the cross section, the deformation pattern of filled body induced by gravity and rainfall infiltration was obtained. Conclusions can be made as follows:

(1) The settlement of filled loess body on flat ground is composed of instantaneous compression and consolidation generated by increasing gravity. The unloading rebound deformation is about $15 \%$ of the deformation induced by increased gravity. The consolidation-induced settlement when gravity force gradually increases is dominating, and this is corresponding to the construction process. Affected by the creep of loess, the secondary consolidation of filled loess makes a continuous increase in the settlement when acceleration rate reaches its target value.

(2) The settlement of loess fill in a valley peaks at the centerline of the valley, and it decreases with the monitoring point away from the centerline. The ground settlement induced by rainfall infiltration is much smaller than the one induced by soil gravity. Insufficient compaction of the filling body in the lower half part has obvious influence on the postconstruction settlement of ground; however, it has little influence on the ground settlement induced by rainfall infiltration. In order to reduce the ground settlement, the filling material especially in the lower part should be densified enough.

(3) The evolution and spatial distribution of deformation of loess filled body in a valley can be clearly shown by the centrifuge model tests. The obtained settlement characteristics during construction, postconstruction, and rainfall infiltration process can provide useful reference for the design so as to control the deformation of loess filling engineering. There is some limitation in the tests; i.e., the variation of suction in unsaturated loess and its influence on the soil behavior are not monitored, and these 
characteristics and effects on the settlement of filled body deserve further study.

\section{Data Availability}

The data used to support the findings of this study are available from the corresponding author upon request.

\section{Conflicts of Interest}

The authors declare no conflicts of interest.

\section{Acknowledgments}

This work was supported by the National Key Research and Development Program of China (Grant no. 2017YFD0800501), Science and Technology Innovation Program of Shaanxi Province of China (2016KTZDSF0302), Key Research and Development Program of Shaanxi Province of China (2020ZDLSF06-03), and the Science and Technology Project from China Machinery Engineering Corporation. The support is gratefully acknowledged.

\section{References}

[1] W.-C. Cheng, G. Li, N. Liu, J. Xu, and S. Horpibulsuk, "Recent massive incidents for subway construction in soft alluvial deposits of Taiwan: a review," Tunnelling and Underground Space Technology, vol. 96, p. 103178, 2020.

[2] Z. Li, S. Yan, L. Liu, B. Dai, and W. Dong, "Long-term deformation analysis of recycled construction waste subgrade filler," Advances in Civil Engineering, vol. 2019, Article ID 5891759, 14 pages, 2019.

[3] T. Lan and J. Wang, "Settlement prediction and differential settlement criterion for heightening and thickening levee," Applied Sciences, vol. 8, no. 12, p. 2392, 2018.

[4] E. Derbyshire, T. A. Dijkstra, I. J. Smalley, and Y. Li, "Failure mechanisms in loess and the effects of moisture content changes on remoulded strength," Quaternary International, vol. 24, pp. 5-15, 1994.

[5] J. Feda, "Collapse of loess upon wetting," Engineering Geology, vol. 25, no. 2-4, pp. 263-269, 1988.

[6] Q. Y. Mu, C. Zhou, and C. W. W. Ng, "Compression and wetting induced volumetric behavior of loess: macro- and micro-investigations," Transportation Geotechnics, vol. 23, p. $100345,2020$.

[7] Q.-Y. Mu, H. Dong, H.-J. Liao, and Y.-J. Dang, "Water retention curves of loess under cyclic wetting and drying," Géotechnique Letters, vol. 10, pp. 1-6, 2020.

[8] S. Singhal, R. S. Sharma, and B. R. Phanikumar, "A laboratory study of collapse behaviour of remoulded loess under controlled wetting and flooding," Geomechanics and Geoengineering, vol. 11, no. 2, pp. 159-163, 2016.

[9] X. Shao, H. Zhang, and Y. Tan, "Collapse behavior and microstructural alteration of remolded loess under graded wetting test," Engineering Geology, vol. 233, pp. 11-22, 2018.

[10] D. Zhang, J. Wang, C. Chen, and S. Wang, "The compression and collapse behaviour of intact loess in suction-monitored triaxial apparatus," Acta Geotechnica, vol. 15, no. 2, pp. 529-548, 2019.

[11] G. Li, F. Wang, W. Ma et al., "Variations in strength and deformation of compacted loess exposed to wetting-drying and freeze-thaw cycles," Cold Regions Science and Technology, vol. 151, pp. 159-167, 2018.

[12] H. Luo, F. Wu, J. Chang, and J. Xu, "Microstructural constraints on geotechnical properties of malan loess: a case study from Zhaojiaan landslide in Shaanxi province, China," Engineering Geology, vol. 236, pp. 60-69, 2018.

[13] U. Al Aqtash and P. Bandini, "Prediction of unsaturated shear strength of an adobe soil from the soil-water characteristic curve," Construction and Building Materials, vol. 98, pp. 892-899, 2015.

[14] C. Zhou, Q. Cheng, and C. W. W. Ng, "Thermal effects on yielding and wetting-induced collapse of recompacted and intact loess," Canadian Geotechnical Journal, vol. 55, pp. 1095-1103, 2018.

[15] W. T. Oh and S. K. Vanapalli, "Modelling the applied vertical stress and settlement relationship of shallow foundations in saturated and unsaturated sand," Canadian Geotechnical Journal, vol. 48, no. 3, pp. 903-914, 2011.

[16] A. A. Abed and P. A. Vermeer, "Numerical simulation of unsaturated soil behaviour," International Journal of Computer Applications in Technology, vol. 34, no. 1, pp. 2-12, 2009.

[17] F. Zhang, L. Zhang, T. Zhou, L. Duan, and C. Shi, "An experimental study on settlement due to the mutual embedding of miscellaneous fill and soft soil," Advances in Civil Engineering, vol. 2020, 10 pages, Article ID 4819605, 2020.

[18] Y. Kim, H. Park, and S. Jeong, "Settlement behavior of shallow foundations in unsaturated soils under rainfall," Sustainability, vol. 9, no. 8, p. 1417, 2017.

[19] H. Li, J. Tao, L. Wei, and Y. Liu, "Explosive compaction technology for loess embankment settlement control: numerical simulation and field implementation," Acta Geotechnica, vol. 15, no. 4, pp. 975-997, 2020.

[20] F. Ma, J. Yang, and X. Bai, "Water sensitivity and microstructure of compacted loess," Transportation Geotechnics, vol. 11, pp. 41-56, 2017.

[21] Y. Zhang, W. Ye, and Z. Wang, "Study on the compaction effect factors of lime-treated loess highway embankments," Civil Engineering Journal, vol. 3, no. 11, pp. 1008-1019, 2017.

[22] X. Lü, D. Xue, Q. Chen, X. Zhai, and M. Huang, "Centrifuge model test and limit equilibrium analysis of the stability of municipal solid waste slopes," Bulletin of Engineering Geology and the Environment, vol. 78, no. 4, pp. 3011-3021, 2019.

[23] S.-H. Cui, X.-J. Pei, H.-Y. Wu, and R.-Q. Huang, "Centrifuge model test of an irrigation-induced loess landslide in the Heifangtai loess platform, northwest China," Journal of Mountain Science, vol. 15, no. 1, pp. 130-143, 2018.

[24] Y. Xu, C. F. Leung, J. Yu, and W. Chen, "Centrifuge model study on settlement of strip footing subject to rising water table in loess," Canadian Geotechnical Journal, vol. 57, no. 7, pp. 992-1005, 2020.

[25] J. Garnier, C. Gaudin, S. M. Springman et al., "Catalogue of scaling laws and similitude questions in geotechnical centrifuge modelling," International Journal of Physical Modelling in Geotechnics, vol. 7, no. 3, pp. 1-23, 2007.

[26] T. Tobita, S. Iai, L. von der Tann, and Y. Yaoi, "Application of the generalised scaling law to saturated ground," International Journal of Physical Modelling in Geotechnics, vol. 11, no. 4, pp. 138-155, 2011. 